Check for updates

Cite this: RSC Adv., 2018, 8, 27805

\title{
Silk fibroin-derived peptide directed silver nanoclusters for cell imaging $\dagger$
}

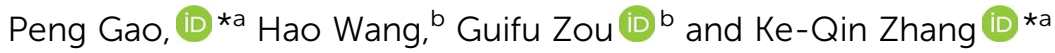

\begin{abstract}
Fluorescent silver nanoclusters (Ag NCs) that are capable of emitting green light have been synthesized using a peptide derived from the $\mathrm{C}$ terminal of silk fibroin heavy chain (CSH) via a one-pot, green, and facile synthesis method. The emission was also found to be stable at the excitation wavelength and the fluorescence quantum yield of Ag NCs was measured to be $1.1 \%$. Matrix assisted laser desorption ionization time of flight mass spectrometry (MALDI-TOF MS) indicated the presence of a range of $\mathrm{Ag}$ species that correspond to Ag1, Ag2, Ag3 and Ag4. Transmission electron microscopic analyses suggested that the formed particles are uniform and well dispersive with an average diameter of $2.5 \mathrm{~nm}$. The Ag NCs were successfully applied to cell imaging in murine preosteoblast MC3T3-E1 cells. Finally, Ag NCs observed by MTT exhibited distinct cytotoxicity at CSH-Ag NCs concentrations of $600 \mu \mathrm{M}$. Based on the concept of utilizing a functional peptide from nature, this study demonstrates a novel approach to fabricate aqueous metal nanoclusters for tracking applications in bioimaging.
\end{abstract}

Received 30th May 2018

Accepted 11th July 2018

DOI: $10.1039 / \mathrm{c} 8 \mathrm{ra} 04607 \mathrm{~g}$

rsc.li/rsc-advances

reduce their surface energy, various chelating ligands, such as

\section{Introduction}

Noble metal nanoclusters (NCs) have gained considerable attention for various applications in biological imaging, chemical sensing, catalysis and therapy due to their unique physical, electrical and optical properties. ${ }^{1-4}$ Generally, metal NCs, comprising several to roughly dozens of metal atoms, are an emerging class of fluorescent materials, which are attracting increasing interests from many scientists. They possess discrete energy level and sizes that approach the Fermi wavelength of electrons and exhibit significant photoluminescence, which is regulated by their sub-nanometer dimensions. Compared to commonly used organic dyes, quantum dots and fluorescent proteins, metal NCs possess several unique characteristics, including tunable photo-properties, ultra-fine sub-nanometer size particles, high selectivity and high biocompatibility, enabling them as a highly attractive alternative for conventional probes. However, to the best of our knowledge, there is limited literature on $\mathrm{Ag} \mathrm{NCs}$ and their applications, relative to that of $\mathrm{Au}$ NCs. ${ }^{5,6}$ This is because silver clusters are more reactive than other metal analogues and tend to grow and form larger nanoparticles. As far as we know, ease of preparation, high quantum yield and high stability under physiological conditions are still the main challenges in the synthesis of Ag NCs. To

${ }^{a}$ National Engineering Laboratory for Modern Silk, College of Textile and Clothing Engineering, Soochow University, Suzhou, 215123, P. R. China. E-mail: pgao116@ 126.com; kqzhang@suda.edu.cn

${ }^{b}$ College of Physics, Optoelectronics and Energy, Collaborative Innovation Center of Suzhou Nano Science and Technology, Soochow University, Suzhou 215006, P. R. China $\dagger$ Electronic supplementary information (ESI) available. See DOI: 10.1039/c8ra04607g proteins, DNA, polymers, dendrimers, thiolates and other small molecules have been successfully used as stabilizing ligands for the synthesis of Ag NCs. ${ }^{7-10}$

Proteins/peptides serve as flexible and effective biotemplates, which have been demonstrated to have great potential for the controlled synthesis of metal NCs with characteristic biofunctions. In the case of peptide templates, Dickson et al. designed three short peptides from nucleolin with minor sequence differences to capture the silver clusters. These silver clusters exhibit similar photophysics to those in the nucleolus, but with narrower emissions at $610 \mathrm{~nm}$ (P1-Ag), $615 \mathrm{~nm}(\mathrm{P} 2-\mathrm{Ag})$, and $630 \mathrm{~nm}(\mathrm{P} 3-\mathrm{Ag})$. MALDI mass spectrometry confirms the presence of silver clusters and their composition, in which $\mathrm{Ag} 2, \mathrm{Ag} 3, \mathrm{Ag} 4$, or $\mathrm{Ag} 5$ are bound to a single peptide. ${ }^{11}$ In the case of BSA, the synthesis of fluorescent BSAAg15 has been accomplished by using denatured BSA as a stabilizing agent and $\mathrm{NaBH}_{4}$ as a reduction agent. The stability of BSA-Ag15 could be further enhanced by the addition of poly(vinyl pyrrolidone) in aqueous solution. ${ }^{12}$ Furthermore, Xie et al. prepared gold nanoclusters of five discrete sizes (Au4, Au8, Au10, Au13, and Au25) by using BSA with a predefined protein conformation. ${ }^{13}$ In conclusion, it has been demonstrated that the protein sequence and conformation as well as the protein size and amino acid content play key roles in controlling the size of the NCs, thus resulting in the formation of metal NCs with different sizes and varied fluorescence properties. Notably, certain proteins/peptides with distinct biological functions and characteristic sequence and conformation were demonstrated and predicted..$^{14,15}$ Currently, numerous proteins/ peptides, including $\mathrm{GSH},{ }^{16,17}$ lysozyme, ${ }^{18} \alpha$-chymotrypsin, ${ }^{19}$ 


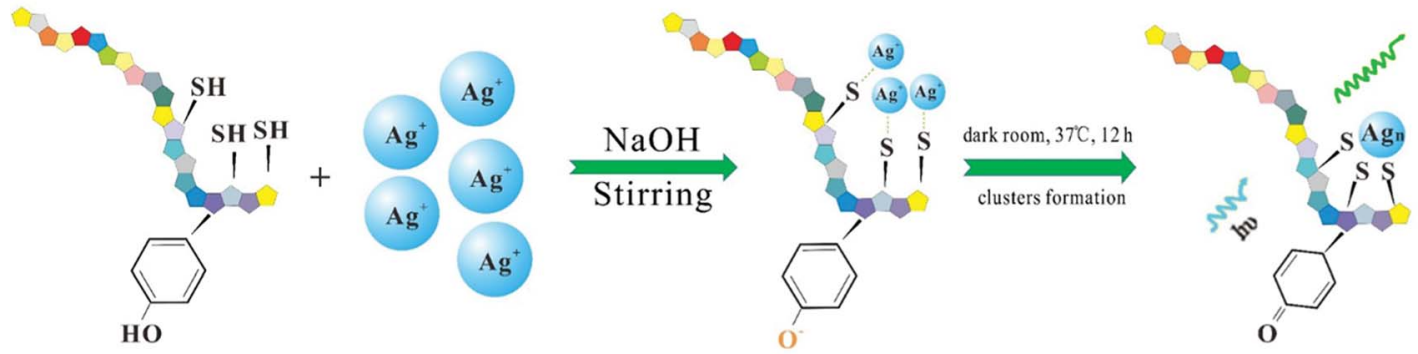

Scheme 1 Schematic of the synthesis of CSH-Ag NCs.

$\mathrm{BSA}^{20}{ }^{20} \mathrm{HAS},{ }^{21}$ and programed peptides, ${ }^{22,23}$ have been successfully adopted as novel biotemplates for the synthesis of Ag NCs. Nevertheless, only a few studies of Ag NCs have been reported using peptide/protein as the capping reagent.

To further explore the potential of silk fibroin and its derivatives, we initially employed one characteristic peptide of silk fibroin to fabricate hydrosoluble fluorescent Ag NCs. As shown in Scheme 1, CSH-Ag NCs with green emission were synthesized via a one pot, facile and green method. The characteristic peptide comprising 58 amino acids was selected from the $\mathrm{C}$ terminus of heavy chain of silk fibroin, featuring three cysteine units, four tyrosine units, and nine basic amino acids. Recent studies have shown that the presence of a thiol group (in cysteine) could facilitate the synthesis of peptide-protected metal NCs with good stability in solution due to the unique metal-sulfur chemistry that is typically strong. ${ }^{22,24}$ We speculate that the peptide could be a potential biotemplate candidate for the synthesis of Ag NCs due to the presence of cysteine, tyrosine and basic amino acids. We observed that the $\mathrm{CSH}-\mathrm{Ag}$ NCs with green emission can easily penetrate the cytomembrane, and hence can be effectively applied for cellular imaging.

\section{Experimental}

\subsection{Materials}

The chemically synthesized peptide was purchased from ChinaPeptides Co., Ltd., according to the pristine sequence data from NCBI, termed as CSH peptide (VSYGAGRGYGQGAGSAASSVSSASSRSYDYSRRNVRKNCGIPRRQLVVKFRALPCVNC, HPLC purified: 90\%). Chlorauric acid was purchased from National Medicines Chemical Reagent Co., Ltd. (Shanghai, China). All reagents were of analytical grade and used without further purification. Water $(18.25 \mathrm{M} \Omega \mathrm{cm})$ used in all experiments was deionized by the Milli-Q Academic purification set (Millipore, Bedford, MA, USA).

\subsection{Synthesis of CSH-Ag NCs}

All glassware was washed with aqua regia and rinsed with ultrapure water. Typically, the synthesis was started with an aqueous $\mathrm{AgNO}_{3}$ solution $\left(32.4 \mu \mathrm{L}, 25 \mathrm{mM}, 37^{\circ} \mathrm{C}\right)$, which was slowly added to $\mathrm{CSH}$ peptide solution $\left(205 \mu \mathrm{L}, 2 \mathrm{mM}, 37^{\circ} \mathrm{C}\right)$. Then, $\mathrm{NaOH}$ solution $(0.5 \mathrm{M}, 5 \mu \mathrm{L})$ was added to achieve a final $\mathrm{pH}$ value of $\sim 10$. After vigorous stirring for $5 \mathrm{~min}$, the reaction was incubated in a baking oven at $37^{\circ} \mathrm{C}$ for $12 \mathrm{~h}$.

\subsection{Characterization of $\mathrm{CSH}-\mathrm{Ag} \mathrm{NCs}$}

Ultraviolet-visible (UV-vis) absorption spectra were recorded using a Shimadzu UV-2450 spectrophotometer. All the photoluminescence (PL) spectra were recorded on a Fluoromax-4 spectrofluorometer (HORIBA Jobin Yvon Inc.) equipped with a $150 \mathrm{~W}$ xenon lamp as the excitation source. The composition of CSH-Ag NCs was analyzed using MALDI-TOF mass spectrometry on a Bruker micro TOF-Q system. The pure peptide and as-synthesized CSH-Ag NCs were simultaneously characterized in a positive linear model using $\alpha$-cyano-4hydroxycinnamic acid (CHCA) as a matrix. Transmission electron microscopy (TEM) images were obtained on a FEI Tecnai F20 microscope operating at $200 \mathrm{kV}$ for measuring the nanostructure and size distribution. The size distribution of $\mathrm{CSH}-\mathrm{Ag}$ NCs was analyzed from TEM images using image J software (ImageJ1.44p, National Institutes of Health, U.S.A.). X-ray photoelectron spectra (XPS) were acquired with a Japan Kratos Axis Ultra HAS spectrometer using a monochromatic $\mathrm{Al} \mathrm{K} \alpha$ source.

\subsection{Cell culture and imaging}

The murine osteoblastic MC3T3-E1 cells (preosteoblast cells) were obtained from the Medical College of Soochow University and maintained in our lab. The cells were expanded in an alpha minimum essential medium ( $\alpha$-MEM, Thermo Fisher Scientific, U.S.A.) containing $10 \%$ fetal bovine serum (FBS, Life Technologies, U.S.A.) and 1\% penicillin/streptomycin (Life Technologies, U.S.A.) in $5 \% \mathrm{CO}_{2}$ humidified incubator at $37{ }^{\circ} \mathrm{C}$. The medium was replaced every $48 \mathrm{~h}$. After culturing in the growth medium until 80-90\% confluence, the cells were harvested for further use.

\subsection{Cytotoxicity}

To assess the cytotoxicity, cell viability assays were carried out with an MTT assay according to the standard manufacturer protocol. MC-3T3 E1 cells $\left(1 \times 10^{4}\right.$ cells per well $)$ were seeded in a 96-well microplate and grown in $\alpha$-MEM for $24 \mathrm{~h}$ in the presence of $5 \% \mathrm{CO}_{2}$ at $37{ }^{\circ} \mathrm{C}$. Then, various concentrations of $\mathrm{Ag}$ NCs $(0-600 \mu \mathrm{M})$ were added to the cells and kept for $24 \mathrm{~h}$ in similar conditions. For the reaction, $7.0 \mu \mathrm{L}$ of MTT was added to each well of the microplate and kept for $2 \mathrm{~h}$ for the formation of formazan. The control experiment was carried out in a similar 
way with various amounts of peptide. All of the experiments were carried out in triplicate. The percentage of cell viability of the control was taken as $100 \%$.

\section{Results and discussion}

\subsection{Synthesis of $\mathrm{CSH}-\mathrm{Ag}$ NCs}

Highly fluorescent Au NCs using aprotinin in aqueous solution were synthesized via a facile one pot method. For the synthesis, the peptide solution was mixed with a similar volume of $\mathrm{AgNO}_{3}$ aqueous solution under thorough stirring. Some of the $\mathrm{Ag}$ ions interacted with the thiol groups of the CSH peptide to form an intermediate product. When $\mathrm{pH}$ was adjusted to the desired value by adding $1 \mathrm{M} \mathrm{NaOH}$ solution, the phenolic group of $\mathrm{Y}$ converted into a negative phenolic ion that reduced $\mathrm{Ag}$ ions to $\mathrm{Ag}$ atoms. The color of the mixed solution turned from pale to brown, indicating the formation of Ag $\mathrm{NCs}^{22}$ The as-prepared CSH-Ag NCs showed significant fluorescence under UV illumination. They were kept in a refrigerator for further use. Overall, this CSH peptide performs the role of a protecting ligand for Ag clusters synthesis.

\subsection{Characterization of the CSH-Ag NCs}

The optical properties of the peptide-Ag clusters were further characterized by ultraviolet-visible (UV-vis) absorption spectroscopy. There were no distinct absorption peaks between 200$350 \mathrm{~nm}$ belonging to the Au clusters. A peak at $520 \mathrm{~nm}$ in a gradient absorption from 350 to $800 \mathrm{~nm}$ was present in the absorption spectrum and was designated as the peptide- $\mathrm{Ag}$ clusters (the red dash line in the inset of Fig. 1). The fluorescence spectrum was also characterized using a Fluoromax-4 spectrofluorometer, which showed that the peptide-Ag NCs (Fig. 1) have maximum excitation and emission peaks at $525 \mathrm{~nm}$ and $550 \mathrm{~nm}$, respectively. The absorption maxima matched the excitation wavelength in photoluminescence spectra. The as-

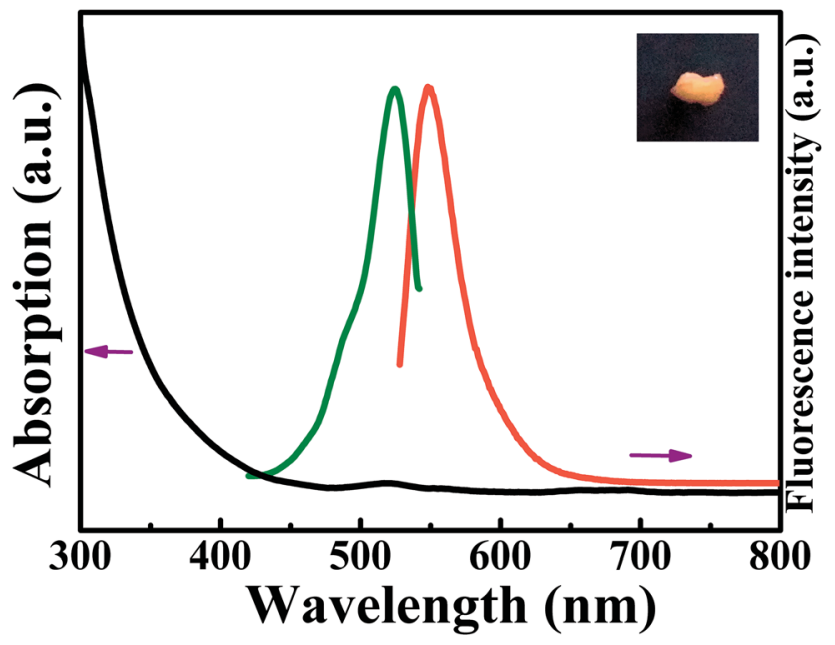

Fig. 1 UV-vis and fluorescence spectra of the as-prepared $\mathrm{CSH}-\mathrm{Ag}$ $\mathrm{NCs}$ aqueous solution (black). Emission of $\mathrm{CSH}-\mathrm{Ag} \mathrm{NCs}$ at $550 \mathrm{~nm}$ excited at $525 \mathrm{~nm}$ spectra of the as-prepared CSH-Ag NCs aqueous solution. prepared $\mathrm{CSH}-\mathrm{Ag}$ NCs solution is transparent under visible light and exhibits green emission under UV light at $365 \mathrm{~nm}$. As shown by the inset of Fig. 1, the lyophilized CSH-Ag NCs powder maintains the corresponding fluorescence emission under visible and UV light. It is notable that both samples were stable in their aqueous solutions and as powder when stored at $4{ }^{\circ} \mathrm{C}$ in a dark room for more than one month (Fig. S1 in the ESI $\dagger$ ). The excitation-independent PL spectrum showed that peptide-Ag NCs exhibited intrinsic fluorescence at $550 \mathrm{~nm}$ with different excitation wavelengths from 400 to $525 \mathrm{~nm}$ (Fig. S2 in the ESI $\dagger$ ). The as-synthesized $\mathrm{CSH}-\mathrm{Ag}$ clusters possess a fluorescence quantum yield of about $1.1 \%$. The quantum yield (QY) of the CSH-Ag NCs was obtained using a $405 \mathrm{~nm}$ Xe laser and calibrated with Rhodamin 6G (Sigma 252433, dye content: $99 \%$ ), according to the emission peak area and absorbance of the peptide-Au clusters and Rhodamin 6G. Matrix-assisted laser desorption/ionization time of flight mass spectrometry (MALDITOF MS) is a general way to identify the well-defined composition of peptide-Ag NCs, including accurate number of $\mathrm{Ag}$ clusters and peptide coating outside the Ag NCs. ${ }^{25}$ Peptide-Ag clusters and the pure peptide were characterized in positive ion mode using $\alpha$-cyano-4-hydroxycinnamic acid (CHCA) as a matrix. The spectrum of the peptide- $\mathrm{Ag}$ clusters was composed of a series of intense peaks between $5.8-6.8 \mathrm{k} \mathrm{m} / \mathrm{z}$. The representative mass spectrum with labeled peaks is shown in the inset of Fig. 2. The spacing between adjacent intense peaks could be matched with the $m / z$ of one intact peptide with one missing silver atom. The peak of $\mathrm{m} / \mathrm{z} 108$ corresponds to the loss of Ag in MALDI-TOF MS studies. All intense peaks correspond to a cluster and the $m / z$ of the intense peaks match the formula of Ag1, Ag2, Ag3 and Ag4 (Fig. 2a). Furthermore, no apparent peaks were observed between $6800-19000 \mathrm{~m} / z$, suggesting that the Ag NCs in aqueous solution was not coated by multiple peptides. As reported previously, biomolecules with the sequence specificity and structure of DNA and the peptide play key roles in determining the composition of the Ag clusters and their optical properties. ${ }^{13,23,26}$ Compared to the results of the Dickson study, our results showed that the sequence dependent peptide affects the accurate formation of Ag NCs. Based on these results, we speculate that different compositions of Ag NCs can be achieved by engineering the sequence of the protein/peptide, particularly with the use of cysteine and basic amino acids as stabilizing reagents. ${ }^{16,27}$ Thus far, a limited amount of research has been conducted towards the precise production of Ag NCs by using engineered peptides. Due to the limitation of high cost associated with long peptides, the hypothesis should be further verified via experiment by using simplified peptides. To characterize the morphology of peptide-Ag NCs, TEM measurements were performed, which indicated that the asprepared $\mathrm{Ag}$ NCs were uniform in size. Furthermore, the mean diameter of CSH-Ag NCs was determined to be around $2.162 \pm 0.67 \mathrm{~nm}$ by measuring the diameters of 116 samples (Fig. 2b and c), which is consistent with previous reports of Ag clusters possessing a small average size. ${ }^{28,29}$ Further probing by HRTEM showed the presence of crystalline particles with a lattice spacing of $0.24 \mathrm{~nm}$, corresponding to the (111) plane of $\mathrm{Ag}(0)$. Due to the presence of basic groups, the uniform 

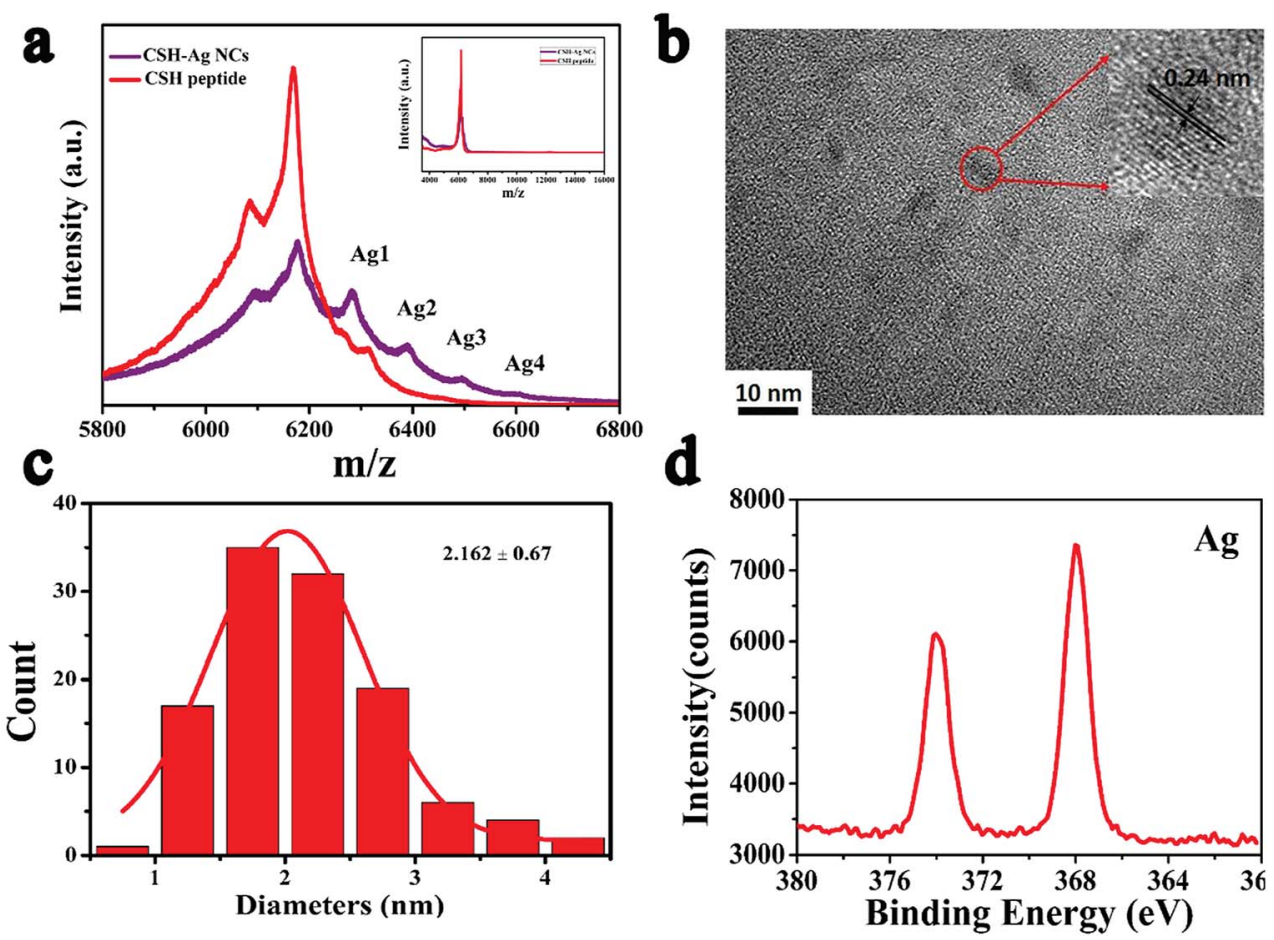

Fig. 2 The photographs of morphology and composition of CSH-Ag NCs. (a) Comparison of one CSH peptide (red) and peptide-Ag NCs (blue) by MALDI-TOF mass spectra, indicating the characteristic peaks are assigned to Ag1, Ag2, Ag3 and Ag4, respectively. The spacing gap between adjacent $\mathrm{m} / \mathrm{z}$ peaks of $\mathrm{CSH}-\mathrm{Ag} \mathrm{NCs}$ (blue) is identified as $\sim 108$. (b) High resolution transmission electron microscopy (HRTEM) images showed the mean size of $\mathrm{Ag} \mathrm{NCs}$ with $10 \mathrm{~nm}$ bar. The image of (inset) gives a lattice spacing of $0.24 \mathrm{~nm}$ corresponding to the (111) plane of Ag(0) (c) size distribution histogram of Ag NCs calculated from the TEM images by counting 116 number. (d) XPS spectrum confirms the CSH-Ag NCs with zero valence form in the $\mathrm{Ag} 3 \mathrm{~d}$ region.

morphology can be explained by the interaction of electrically charged groups of the basic amino acid in the peptide, which prevents further aggregation of the Ag clusters. ${ }^{30,31}$ Furthermore, the crystal form of the nanoparticles was examined, which indicated the existence of Ag (Fig. S3 in the ESI†). EDAX spectrum supported the presence of $\mathrm{Ag}$ and $\mathrm{S}$ of the $\mathrm{CSH}-\mathrm{Ag}$ NCs in the sample along with the quantification data. The quantification data suggest that the $\mathrm{Ag}: \mathrm{S}$ ratio is in good agreement with the theoretical value (Fig. S4 in the ESI†). To confirm the interaction between the peptide and $\mathrm{Ag}$ clusters, the composition and the chemical oxidation state of the Ag NCs were determined by X-ray photoelectron spectroscopy (XPS). As shown in Fig. 2d, the two intense peaks at $\sim 368.12 \mathrm{eV}$ and $\sim 374.12 \mathrm{eV}$ in the $\mathrm{Ag} 3 \mathrm{~d}$ region of the XPS spectrum were assigned to the observed peaks of $\mathrm{Ag} 3 \mathrm{~d} 5 / 2$ and $\mathrm{Ag} 3 \mathrm{~d} 3 / 2$. This indicates the existence of $\mathrm{Ag}$ clusters with a zero valence form in the peptide-Ag cluster structure.

\subsection{Cellular imaging applications}

To demonstrate the potential biomedical application of $\mathrm{CSH}-\mathrm{Ag}$ NCs, the peptide-Ag NCs were used to verify their ability to stain cells. After incubating with murine preosteoblast MC3T3-E1 cells for $2 \mathrm{~h}$, the Ag NCs observed by laser confocal fluorescence imaging show significant fluorescence emission in the live cells. ${ }^{32,33}$ As shown in Fig. 3, the subcellular localization of the Ag clusters indicated that cell nuclei were primarily occupied by Ag NCs because of their distinct color in the merged images. Notably, staining the organelles of cells is an important issue in clinical diagnosis and molecular studies, particularly for staining the nucleus in sub-cellular organelle imaging. ${ }^{11,34}$ This result showed a novel approach for the easy fabrication and fluorescent staining of cell nuclei based on a silk fibroin derived peptide. Due the fact that the peptide-Ag NCs possess ultra-small size and a more positive charge, the reason for uptake and imaging of peptide-Ag NCs may be ascribed to transport through entry by endocytosis. Furthermore, we speculated that the peptide could act like a new class of cell penetrating peptides (CPPs) because of the abundant positive charges on the surface of the peptide. ${ }^{34,35}$ The biological role of the peptide, however, should be investigated in future experiments.

\subsection{The test of cytotoxicity}

To assess cellular toxicity of the $\mathrm{CSH}-\mathrm{Ag}$ nanoclusters, their cellular cytotoxicity to the MC3T3-E1 cells was investigated using an MTT assay. As shown in Fig. S5 and S6, $\dagger$ five different concentrations of $\mathrm{CSH}-\mathrm{Ag}$ NCs over five time intervals were tested and the apparent cytotoxicity was observed by determining the cell viability of the treated versus untreated cells. The results indicated that the $\mathrm{CSH}-\mathrm{Ag}$ NCs caused a gradual decrease in cell viability in a time and dose dependent manner. Collectively, we speculate that Ag NCs functionalized by silk 


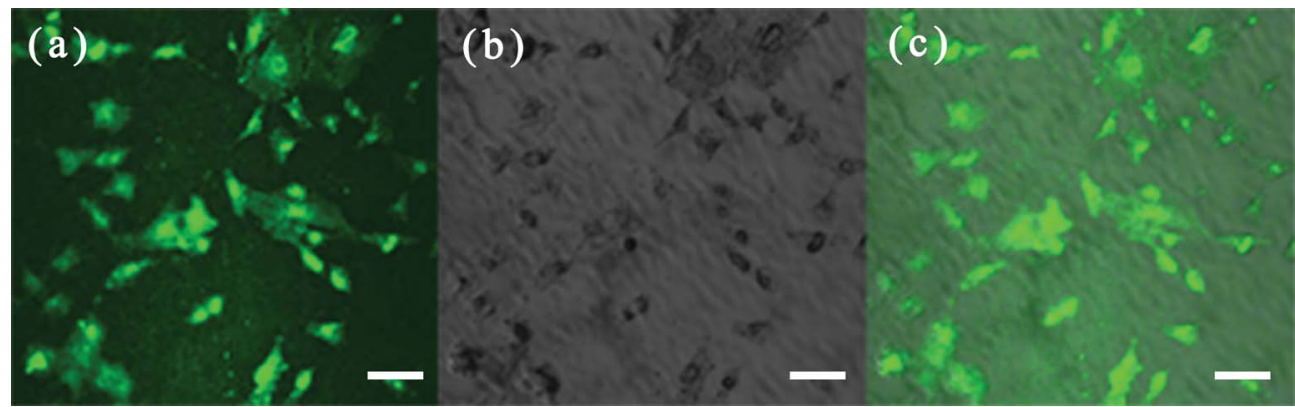

Fig. 3 The confocal microscope images of cellular staining of the CSH-Ag NCs in murine preosteoblast MC-3T3 cells with 405 nm excitation (a) fluorescent image of CSH-Ag NCs (b) bright field (c) merged image (scale bar: $50 \mu \mathrm{m}$ ).

fibroin derived peptide synergistically contribute to significant cytotoxicity effects in the MC3T3 cells. ${ }^{34,36,37}$

\section{Conclusion}

Herein, we report the first instance of the use of silk fibroin derived peptide from the Bombyx mori silkworm to synthesize $\mathrm{Ag}$ NCs via a one-pot green method. The as-synthesized Ag NCs with green emission showed a fluorescence peak at $550 \mathrm{~nm}$ in aqueous solution. The well-defined composition of peptide-Ag NCs was assigned as Ag1, Ag2, Ag3 and Ag4 using MALDI-TOF MS. The CSH-Ag NCs maintain stable and bright fluorescence in aqueous solution, which could be used for cellular imaging. Overall, this study verified the viability of amino acid sequence dependent peptides for the synthesis of $\mathrm{Ag}$ NCs and their synergistic functionality between the peptide/protein and $\mathrm{Ag}$ clusters in cell imaging. Because of the increasing interest of peptides in pharmaceutical research and development and the approximately 140 peptide therapeutics currently being evaluated in clinical trials, ${ }^{38}$ future efforts could be devoted to explore to usage of functional peptides or proteins that originate from natural organisms. Moreover, it is desirable to understand the relationship of sequence specificity and growth mechanism of the metal cores. Inspired by this study, we believe that current research will intensively promote the rational exploration of silk fibroin resources and the fabrication of protein/peptide functionalized metal nanoclusters for biomedical applications guided by imaging.

\section{Conflicts of interest}

There is no competing conflict of interest to declare.

\section{Acknowledgements}

The authors are grateful for the support from the National Science Foundation of China under Grants 51203108, 51073113, 91027039, and 51373110, the Natural Science Foundation of Jiangsu Province of China under Grants BK2011355 and BK20130313, Natural Science Foundation of the Jiangsu Higher Education Institutions of China under Grants 11KJB430011 and 10KJA540046, and the Nanotechnology
Foundation of Suzhou under Grant ZXG2013037. We also acknowledge support from the Priority Academic Program Development of Jiangsu Higher Education Institutions (PAPD), Qing Lan Project for Excellent Scientific and Technological Innovation Team of Jiangsu Province (2012), and Project for Jiangsu Scientific and Technological Innovation Team (2013).

\section{Notes and references}

1 Y. Tao, M. Li, J. Ren and X. Qu, Chem. Soc. Rev., 2015, 44, 8636-8663.

2 M. Ammu and P. Thalappil, Part. Part. Syst. Charact., 2014, 31, 1017-1053.

3 S. Choi, R. M. Dickson and J. Yu, Chem. Soc. Rev., 2012, 41, 1867-1891.

4 Y. Lu and W. Chen, Chem. Soc. Rev., 2012, 41, 3594-3623.

5 Z. Luo, K. Zheng and J. Xie, Chem. Commun., 2014, 50, 51435155.

6 X. Hangxun and S. Kenneth Suslick, Adv. Mater., 2010, 22, 1078-1082.

7 I. Diez and R. H. A. Ras, Nanoscale, 2011, 3, 1963-1970.

8 W. Wang, J. Li, J. Fan, W. Ning, B. Liu and C. Tong, Sens. Actuators, B, 2018, 267, 174-180.

9 L. Shang and S. Dong, Chem. Commun., 2008, 1088-1090, DOI: $10.1039 / \mathrm{B} 717728 \mathrm{C}$.

10 N. Makarava, A. Parfenov and I. V. Baskakov, Biophys. J., 2005, 89, 572-580.

11 Y. Junhua, S. A. Patel and R. M. Dickson, Angew. Chem., 2007, 119, 2074-2076.

12 A. Mathew, P. R. Sajanlal and T. Pradeep, J. Mater. Chem., 2011, 21, 11205-11212.

13 Y. Yu, Z. Luo, C. S. Teo, Y. N. Tan and J. Xie, Chem. Commun., 2013, 49, 9740-9742.

14 R. de la Rica and H. Matsui, Chem. Soc. Rev., 2010, 39, 34993509.

15 P. Radivojac, W. T. Clark, T. R. Oron, A. M. Schnoes, T. Wittkop, A. Sokolov, K. Graim, C. Funk, K. Verspoor, A. Ben-Hur, G. Pandey, J. M. Yunes, A. S. Talwalkar, S. Repo, M. L. Souza, D. Piovesan, R. Casadio, Z. Wang, J. Cheng, H. Fang, J. Gough, P. Koskinen, P. Törönen, J. Nokso-Koivisto, L. Holm, D. Cozzetto, D. W. A. Buchan, K. Bryson, D. T. Jones, B. Limaye, H. Inamdar, A. Datta, 
S. K. Manjari, R. Joshi, M. Chitale, D. Kihara, A. M. Lisewski, S. Erdin, E. Venner, O. Lichtarge, R. Rentzsch, H. Yang, A. E. Romero, P. Bhat, A. Paccanaro, T. Hamp, R. Kaßner, S. Seemayer, E. Vicedo, C. Schaefer, D. Achten, F. Auer, A. Boehm, T. Braun, M. Hecht, M. Heron, P. Hönigschmid, T. A. Hopf, S. Kaufmann, M. Kiening, D. Krompass, C. Landerer, Y. Mahlich, M. Roos, J. Björne, T. Salakoski, A. Wong, H. Shatkay, F. Gatzmann, I. Sommer, M. N. Wass, M. J. E. Sternberg, N. Škunca, F. Supek, M. Bošnjak, P. Panov, S. Džeroski, T. Šmuc, Y. A. I. Kourmpetis, A. D. J. van Dijk, C. J. F. t. Braak, Y. Zhou, Q. Gong, X. Dong, W. Tian, M. Falda, P. Fontana, E. Lavezzo, B. Di Camillo, S. Toppo, L. Lan, N. Djuric, Y. Guo, S. Vucetic, A. Bairoch, M. Linial, P. C. Babbitt, S. E. Brenner, C. Orengo, B. Rost, S. D. Mooney and I. Friedberg, Nat. Methods, 2013, 10, 221.

16 X. Yuan, Z. Luo, Q. Zhang, X. Zhang, Y. Zheng, J. Y. Lee and J. Xie, ACS Nano, 2011, 5, 8800-8808.

17 K. Zheng, M. I. Setyawati, T.-P. Lim, D. T. Leong and J. Xie, ACS Nano, 2016, 10, 7934-7942.

18 T. Zhou, Y. Huang, W. Li, Z. Cai, F. Luo, C. J. Yang and X. Chen, Nanoscale, 2012, 4, 5312-5315.

19 S. S. Narayanan and S. K. Pal, J. Phys. Chem. C, 2008, 112, 4874-4879.

20 C. Guo and J. Irudayaraj, Anal. Chem., 2011, 83, 2883-2889.

21 L. Shang, R. M. Dörlich, V. Trouillet, M. Bruns and G. Ulrich Nienhaus, Nano Res., 2012, 5, 531-542.

22 Y. Cui, Y. Wang, R. Liu, Z. Sun, Y. Wei, Y. Zhao and X. Gao, ACS Nano, 2011, 5, 8684-8689.

23 V. A. Morozov and M. Y. Ogawa, Inorg. Chem., 2013, 52, 91669168.

24 N. Goswami, K. Zheng and J. Xie, Nanoscale, 2014, 6, 1332813347.
25 Y. Wang, Y. Cui, R. Liu, Y. Wei, X. Jiang, H. Zhu, L. Gao, Y. Zhao, Z. Chai and X. Gao, Chem. Commun., 2013, 49, 10724-10726.

26 Y. N. Tan, J. Y. Lee and D. I. C. Wang, J. Am. Chem. Soc., 2010, 132, 5677-5686.

27 J. Yu, S. A. Patel and R. M. Dickson, Angew. Chem., 2007, 119, 2074-2076.

28 Y. Teng, X. Yang, L. Han and E. Wang, Chem.-Eur. J., 2014, 20, 1111-1115.

29 X.-D. Zhang, J. Chen, Z. Luo, D. Wu, X. Shen, S.-S. Song, Y.-M. Sun, P.-X. Liu, J. Zhao, S. Huo, S. Fan, F. Fan, X.-J. Liang and J. Xie, Adv. Healthcare Mater., 2014, 3, 133141.

30 Z. Li, H. Peng, J. Liu, Y. Tian, W. Yang, J. Yao, Z. Shao and X. Chen, ACS Appl. Mater. Interfaces, 2018, 10, 83-90.

31 S. Ling, H. Liang, Z. Li, L. Ma, J. Yao, Z. Shao and X. Chen, J. Mater. Chem. B, 2016, 4, 3643-3650.

32 S. Xu, H. Yang, K. Zhao, J. Li, L. Mei, Y. Xie and A. Deng, RSC Adv., 2015, 5, 11343-11348.

33 Z. Sun, Y. Wang, Y. Wei, R. Liu, H. Zhu, Y. Cui, Y. Zhao and X. Gao, Chem. Commun., 2011, 47, 11960-11962.

34 Y. Wang, Y. Cui, Y. Zhao, R. Liu, Z. Sun, W. Li and X. Gao, Chem. Commun., 2012, 48, 871-873.

35 D. M. Copolovici, K. Langel, E. Eriste and Ü. Langel, ACS Nano, 2014, 8, 1972-1994.

36 C. Zhang, K. Wang, C. Li, Y. Liu, H. Fu, F. Pan and D. Cui, J. Mater. Chem. B, 2014, 2, 6931-6938.

37 Y. Lu, Y. Chi, L. Feng, D. Yuhang, Z. Zhikun and Y. Dayong, Small, 2018, 14, 1800185.

38 K. Fosgerau and T. Hoffmann, Drug Discovery Today, 2015, 20, 122-128. 